\title{
EDITORIAL
}

\section{Changing of the Guard at Molecular Imaging \& Biology}

\author{
Jason S. Lewis
}

Molecular Imaging and Biology \& Memorial Sloan Kettering Cancer Center, New York City, USA

After nearly 10 years (May 2010-December 2019) of distinguished service as Editor-in-Chief of Molecular Imaging \& Biology (MIB), Dr. Raymond Gibson (Fig. 1) has decided to step down and pass the baton. Dr. Gibson trained in organic chemistry and medicinal chemistry and undertook an NIH post-doctoral fellowship to conduct studies on the nicotinic acetylcholine receptor. The studies he initiated on the muscarinic receptor while at George Washington University led to the development of $4-\left[{ }^{123} \mathrm{I}\right]$ Iodo-QNB, which provided the first images in humans of the receptor distribution in healthy individuals and those with various CNS disorders. He co-founded the Society of Non-invasive Imaging in Drug Development, and spent 20 years at Merck Research Laboratories, where he helped develop and characterize imaging probes for the NMDA receptor, the angiotensin receptor, endothelin receptor, CCK-A receptor, NK1 receptor, NPY 5 receptor, mGluR5 receptor, and CB1 receptor.

Since Dr. Gibson took the helm from Professor Jorge R. Barrio, $M I B$ has seen its impact factor increase from 2.467 in 2009 to 3.341 in 2019. Through his hard work, scholarship, and devotion to excellence, he has overseen the publication of 1128 original research contribution and review articles. In 2018, the journal received more than

Correspondence to: Jason Lewis; e-mail: lewisj2@mskcc.org
400 article submissions from over 39 countries! Dr. Gibson's tenure coincided with that of Lorraine Gibson as Managing Editor. Lorraine kept the trains running on time and ensured timeliness and quality, from the early review process to the final publication of an article. In $M I B$, Dr. Ray Gibson and Lorraine Gibson (Fig. 2) leave behind the premier international journal for publishing the latest and most transformative work in molecular imaging, from bench side to human study.

On January 1, 2020, I (Fig. 3) was honored to accept the baton from Dr. Gibson and take over the role of Editor-inChief-I have some very large shoes to fill! I will be assisted by Dr. Rosemery Membreno (Fig. 4) and Dr. Marty Pagel (Fig. 5). Rosemery will be the new Managing Editor; she obtained her PhD in Chemistry in 2018 working with Dr. Brian Zeglis of Hunter College and has extensive experience in molecular imaging. Dr. Pagel of MD Anderson Cancer Center will be the Deputy Editor-in-Chief and will also ensure modality balance in the journal. Dr. Pagel is a Professor and Deputy Chair, Department of Cancer Systems Imaging, Division of Diagnostic Imaging, The University of Texas MD Anderson Cancer Center, Houston, TX. He is a world-renowned expert in developing new molecular imaging methods that evaluate biomarkers of the tumor microenvironment. Going forward, we will be supported by Springer editors Jack Bromley, Journal Development Editor and Stefanie Mangold, Senior Editor, Journals Medicine \& Life Sciences as well as Jesson Austria and Joe Cerami from Springer Nature. 


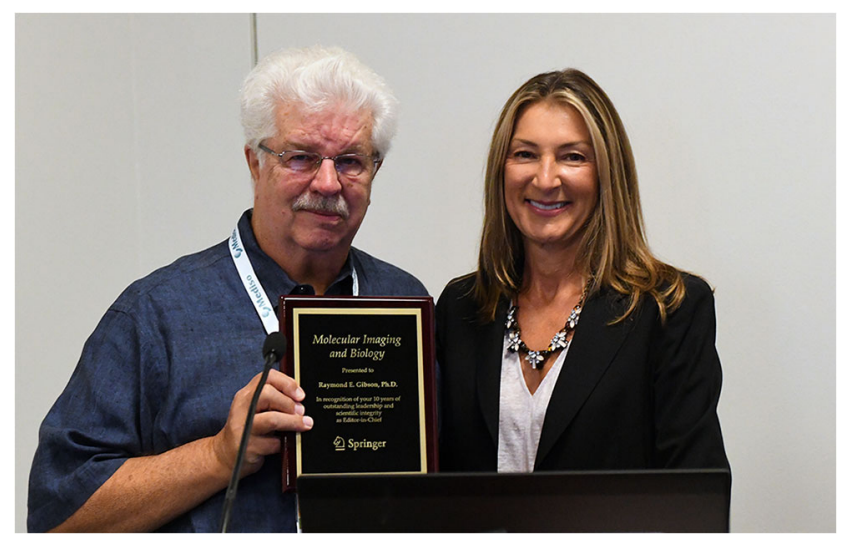

Fig. 1. Dr. Ray Gibson receiving a plaque in recognition of his work by MIB publisher, Ms. Victoria Ferrara (Springer Science).

$M I B$ is the official journal of the World Molecular Imaging Society, the European Society for Molecular Imaging, and the Federation of Asian Societies for Molecular Imaging - and a new highly diverse editorial board has been convened to represent the global nature of this publication. We are also taking this opportunity to change the editorial board to reflect the current status and directions of our field. As you can see from the new mast head, we have new roles within the Editorial board:

Consulting Editors: Some of the most senior scientists in our discipline will act as advisors to myself and Dr. Pagel, helping us steer the journal in the right direction and aiding us in any conflicts or issues that may arise.

Regional Editors: Advisors to myself and Dr. Pagel will represent their regional societies (ESMI, FASMI) and help steer the journal in the right direction.

Senior Editors: True specialists in their respective fields of molecular imaging will review submitted manuscripts and make the final recommendation decision upon completion.

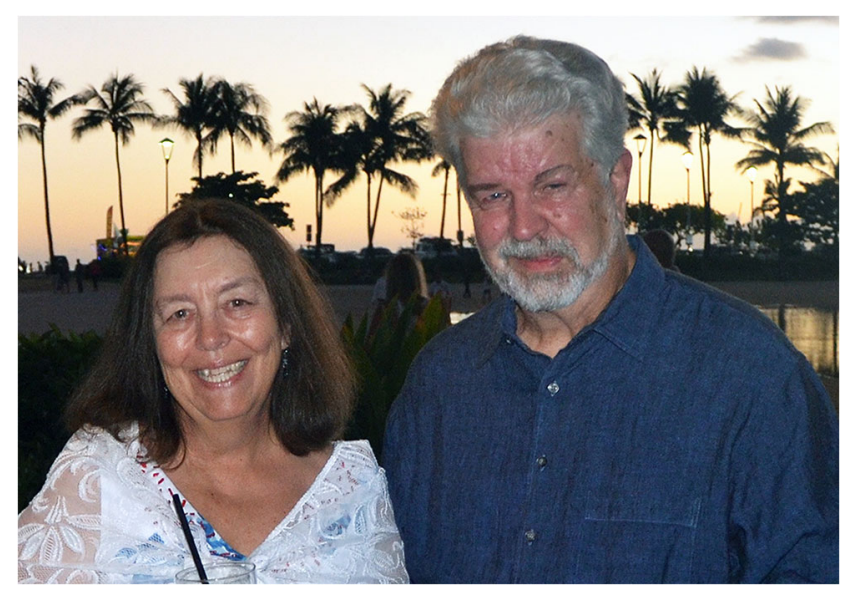

Fig. 2. Dr. Ray Gibson and Lorraine Gibson (Managing Editor) in Hawaii in 2015.

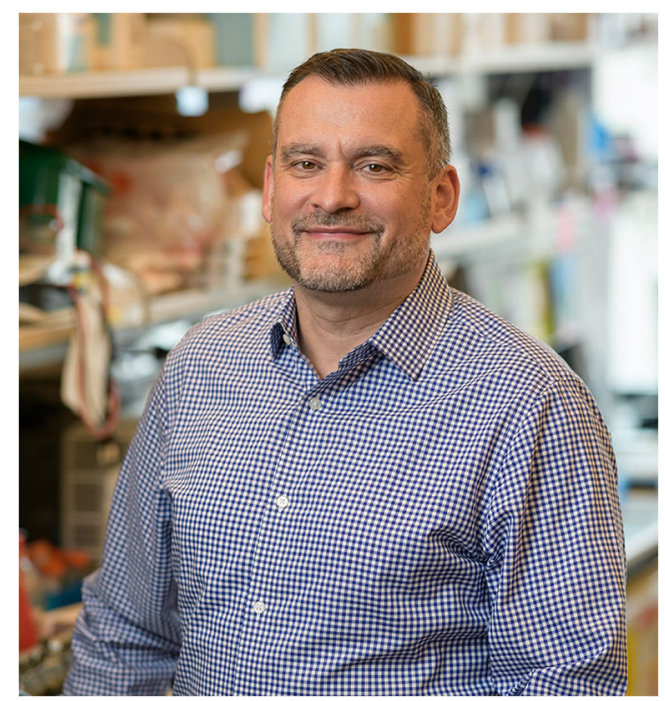

Fig. 3. Professor Jason S. Lewis (Memorial Sloan Kettering Cancer Center), new MIB Editor-in-Chief.

Along with the new editorial board, we are excited to implement additional changes, including a new MIB cover that features an image from the current issue, an expanded social media presence, a "mentored" review system where trainees can be involved and credited in the review process, and the continuation of annual awards including Best Clinical Paper, Best Preclinical Paper, and Image of the Year.

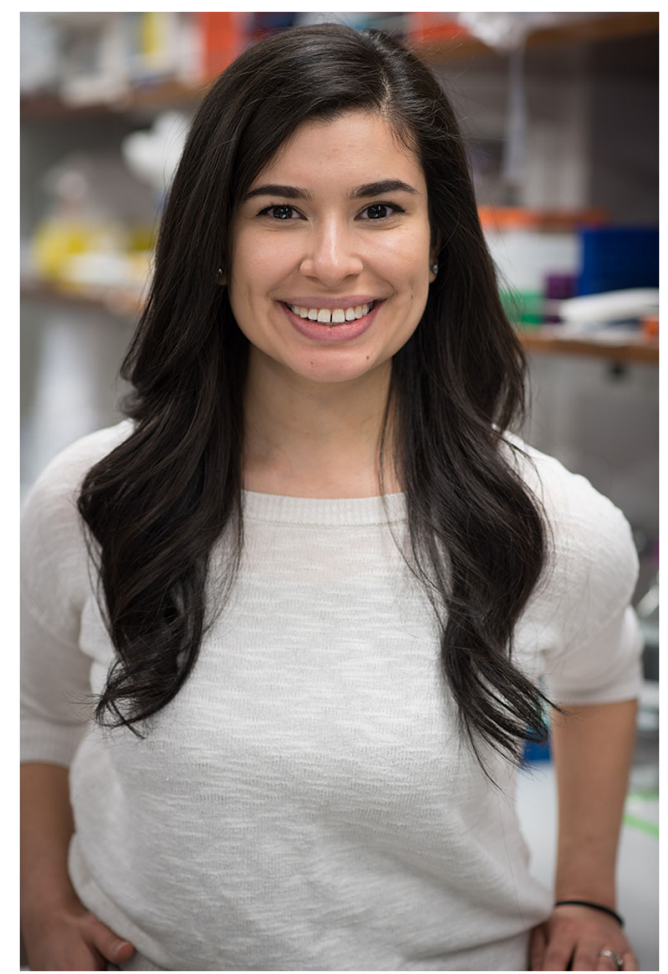

Fig. 4. Dr. Rosemery Membreno (World Molecular Imaging Society), new Managing Editor. 


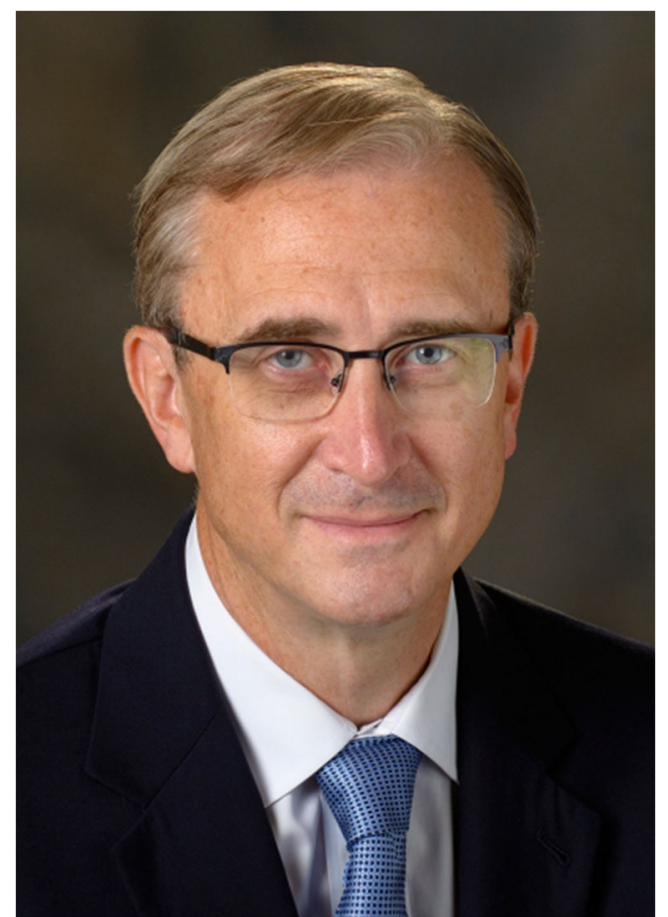

I am hoping you can join us in this endeavor by continuing to submit your highest quality molecular imaging work to ensure $M I B$ remains at the pinnacle of scientific scholarship and dissemination.

Compliance with Ethical Standards

\section{Conflict of Interest}

The author declares that he has no conflict of interest.

Publisher's Note Springer Nature remains neutral with regard to jurisdictional claims in published maps and institutional affiliations.

Fig. 5. Professor Marty Pagel (MD Anderson Cancer Center), new MIB Deputy Editor-in-Chief. 